\title{
Rapid assessment of maternal activity among rural Indian mothers (Pune Maternal Nutrition Study)
}

\author{
AN Kanade ${ }^{1}$, S Rao $^{1, *}$, CS Yajnik ${ }^{2}$, BM Margetts $^{3}$ and CHD Fall ${ }^{4}$ \\ 'Biometry \& Nutrition Group, Agharkar Research Institute, GG Agarkar Road, Pune 411 004, India: ${ }^{2}$ Diabetes Unit, \\ KEM Hospital Research Centre, Pune, India: ${ }^{3}$ Institute of Human Nutrition, University of Southampton, Southampton, \\ UK: ${ }^{4}$ Medical Research Council Environmental Epidemiology Unit, Southampton, UK
}

Submitted 8 July 2004: Accepted 9 December 2004

\begin{abstract}
Objective: To develop an activity questionnaire for objective and rapid assessment of maternal habitual physical activity with the aim of describing its relationship with birth size.

Design: Prospective observational study.

Setting: Six villages near Pune, Maharashtra, India.

Subjects: Seven hundred and ninety-seven rural Indian mothers were studied after excluding abortions and termination of pregnancies, foetal anomalies, etc.

Method: Principal components analysis (PCA) was used to identify a few leading questions from an elaborate questionnaire involving 36 questions related to 14 typical maternal activities.

Results: On the basis of high loading (>0.8), PCA identified three activities, i.e. farming, fetching water and washing clothes. Questions and sub-questions related to these activities only were considered for defining an activity score for rapid assessment. Validation of this new activity score, with the score based on the elaborate questionnaire, showed $70 \%$ sensitivity as well as specificity. New activity scores showed strong inverse relationships similar to those observed using the elaborate questionnaire, at early as well as late gestation, with neonatal head circumference $(P=0.001$ and 0.055$)$ and mid-arm circumference $(P=0.02$ and 0.03$)$. Conclusions: Simple questionnaires, based on leading activities identified by PCA, can be as informative as longer and detailed questionnaires. This method has potential for adaptation, especially in rural communities in developing countries.
\end{abstract}

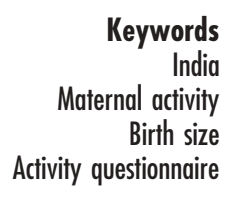

Maternal undernutrition is known to be one of the major determinants of low birth weight in many developing countries like India ${ }^{1}$. However, it cannot be denied that in communities where women are involved in hard work such as farming activities expending higher energy, in addition to domestic chores, consideration of physical activity becomes essential. Direct methods of measuring energy expenditure are expensive and complicated to perform in field conditions, especially in rural India. Moreover, the sophisticated equipment used in such measurements is culturally unacceptable and disruptive to the rural lifestyle of the women. On the other hand, one of the commonly used indirect methods of measuring energy expenditure, the simple diary method, is impractical because the majority of women are illiterate.

A large number of alternative approaches have emerged in the literature, such as simple categorisation of subjects as 'active' and 'non-active', 7-day activity recall ${ }^{3,4}$ or 24-hour recall ${ }^{5}$, using activity questionnaires. Activity questionnaires are considered suitable for epidemiological studies because they require no equipment, are less expensive and do not interfere with subjects' usual activity $^{5}$. The focus is often to rank subjects in a few broad categories from sedentary to very active. They have been used in observational studies to discriminate physical activity at work, during leisure time and during sports ${ }^{6-8}$, the dimensions of habitual activity most commonly distinguished.

Studies reported in the literature indicate that activity questionnaires can yield reliable data for assessing habitual physical activity ${ }^{9}$ even in the absence of an acceptable validation standard against which to compare the questionnaire ${ }^{10,11}$. However, the importance of such questionnaires will be increased tremendously if their association with any health parameter is also established.

Recently, we have shown that an activity questionnaire developed by incorporating community specifics was able 
to bring out its inverse relationship with birth size ${ }^{12}$. However, this questionnaire was elaborate and timeconsuming. Since rural women are preoccupied with their daily routine work, they are often reluctant to respond to such elaborate questionnaires. Therefore, there is a need to develop questionnaires for objective and rapid assessment of maternal habitual physical activity. In addition to identifying women engaged in light and heavy activities, we would also like to explore the possibility of whether such a questionnaire can also discriminate between the birth size of their babies. In that case it would be an additional benefit in a large-scale field studies. In the present study, a rapid assessment questionnaire (RAQ) was developed by using principal components analysis (PCA) to identify a few leading questions from an elaborate activity questionnaire used in an earlier prospective study on rural Indian women ${ }^{12}$ and was validated.

\section{Materials and methods}

\section{Subjects}

The study was undertaken in six villages located $40-50 \mathrm{~km}$ from Pune City and covered a population of approximately 35000. The area is drought-prone and most families live by subsistence farming on small landholdings. The majority of women (75\%) work on their farms or work as labourers in addition to performing domestic chores, which are tedious and hard. The women participating in the present study were young (mean age 21.4 \pm 3.5 years), short (mean height $151.9 \pm 5.1 \mathrm{~cm}$ ), light (mean weight $41.7 \pm 5.1 \mathrm{~kg}$ ) and thin (mean body mass index (BMI) $18.1 \pm 1.9 \mathrm{~kg} \mathrm{~m}^{-2}$ ). Twenty-three per cent of the women had a pre-pregnant body weight below $38 \mathrm{~kg}$ and $9 \%$ were shorter than $145 \mathrm{~cm}$. These are the cut-offs considered to pose a high risk for low birth weight ${ }^{13}$. BMI below $17 \mathrm{~kg} \mathrm{~m}^{-2}$ was found for $31.3 \%$ of the women, indicating severe chronic energy deficiency ${ }^{14}$. Full details of the study including dietary intakes have been reported previously $^{15}$.

All women who reported missing a period between June 1994 and April 1996 were enrolled in the study (1102 women). Of these, 797 women (after excluding abortions and termination of pregnancies, foetal anomalies, multiple pregnancies) were observed until the end of the study. After confirmation of the pregnancy, women were interviewed twice during pregnancy (at $18 \pm 2$ and $28 \pm 2$ weeks of gestation) for assessing physical activity using the elaborate activity questionnaire (Appendix), which was developed during the pre-recruitment phase. Various measurements were obtained for their babies within $72 \mathrm{~h}$ of birth.

\section{Activity questionnaire}

The elaborate activity questionnaire was developed after incorporating community specifics obtained from focus group discussions. The questionnaire consisted of 36 subquestions related to 14 different major daily activities (Appendix). Using published data for the energy expenditure of various activities ${ }^{16}$, a weighted score was derived for all activities in the questionnaire such that a higher weighted score reflected heavier activity. This questionnaire was field-tested and validated with a detailed observer-maintained diary ${ }^{12}$.

\section{Statistical methods}

PCA was used to identify a few leading questions, from the elaborate questionnaire, to describe the most meaningful underlying dimensions of habitual physical activity. For this purpose, the method of varimax rotation was used. Only components with an eigenvalue $>1.0$ were retained for the final rotated solutions. The first component accounts for the largest amount of variability in maternal activity, followed by successive components with progressively smaller proportions of total variance. Each component consists of a few important activities. Based on the activity with the highest loading from each component, a new activity score was developed. This score was then used in multiple linear regression analysis (MLRA) to study its relationship with variables such as birth weight, length and head circumference. On the basis of tertile values of activity scores obtained by each of the questionnaires, women were cross-classified in a $3 \times 3$ contingency table and chi-square analysis was used to examine the association between the two activity questionnaires. Sensitivity (for identifying women doing high activity, i.e. women in the highest tertile of activity) and specificity (for identifying women doing low activity, i.e. women in the lowest tertile of activity) of the newly developed questionnaire were obtained. All data were analysed using SPSS/PC+11.0 (SPSS Inc., Chicago, IL, USA).

\section{Results}

\section{Daily activity pattern}

The activity pattern of the rural mothers in the main study based on the elaborate questionnaire (Table 1) shows that $67 \%$ of women worked on the farm, and of these, $90 \%$ worked for a full day. In a previous study we observed that most farming activities which required prolonged bending, squatting or standing were labelled as 'female tasks'. These farming activities had the highest contribution to the total daily score (38.7\%).

Furthermore, it can be seen that these women did not escape from domestic activities. The majority of the women (about 90\%) did cooking, washing clothes and washing utensils as their main domestic activities. Over $85 \%$ of women fetched water and made an average of two trips per day to the well, carrying at least two containers at a time. Fetching water contributed on average $17.6 \%$ to the 
Table 1 Activity pattern of the rural women during gestation

\begin{tabular}{|c|c|c|c|c|}
\hline \multirow[b]{2}{*}{ Activity } & \multicolumn{2}{|r|}{ 18th week $(n=779)^{*}$} & \multicolumn{2}{|r|}{ 28th week $(n=736)^{*}$} \\
\hline & $\%$ of women & Contribution (\%) to day's activity score & $\%$ of women & Contribution (\%) to day's activity score \\
\hline Rest in afternoon & 80.5 & $10.11 \pm 3.59 \dagger$ & 86.3 & $11.08 \pm 4.48$ \\
\hline Watching TV & 47.4 & $8.62 \pm 3.74$ & 47.7 & $9.66 \pm 4.14$ \\
\hline \multicolumn{5}{|l|}{ Cooking roties } \\
\hline Morning & 67.2 & $4.63 \pm 2.54$ & 67.8 & $5.03 \pm 2.64$ \\
\hline Evening & 87.5 & $3.83 \pm 1.85$ & 84.9 & $4.23 \pm 1.95$ \\
\hline Both & 58.1 & $8.71 \pm 4.31$ & 58.0 & $9.37 \pm 4.33$ \\
\hline Washing clothes & 92.4 & $7.92 \pm 3.42$ & 90.5 & $8.77 \pm 3.95$ \\
\hline Washing utensils & 95.1 & $7.87 \pm 3.59$ & 93.2 & $8.74 \pm 4.05$ \\
\hline Breast-feeding & 17.9 & $1.70 \pm 1.38$ & 4.1 & $1.74 \pm 1.71$ \\
\hline Care of animals & 57.1 & $6.32 \pm 4.82$ & 55.8 & $7.04 \pm 5.64$ \\
\hline Milking & 19.4 & $1.94 \pm 1.04$ & 18.1 & $2.15 \pm 1.54$ \\
\hline Fetching firewood & 64.8 & $2.70 \pm 1.93$ & 64.1 & $2.68 \pm 1.81$ \\
\hline Near & 83.8 & $2.29 \pm 1.43$ & 89.4 & $2.37 \pm 1.28$ \\
\hline Far & 16.2 & $4.83 \pm 2.66$ & 10.6 & $5.26 \pm 3.15$ \\
\hline Fetching water & 86.6 & $17.61 \pm 11.72$ & 80.8 & $18.81 \pm 11.84$ \\
\hline Near & 77.3 & $14.24 \pm 8.61$ & 73.9 & $14.98 \pm 8.89$ \\
\hline Midway & 7.4 & $23.10 \pm 10.69$ & 8.4 & $25.75 \pm 10.97$ \\
\hline Far & 15.3 & $31.91 \pm 13.86$ & 1.8 & $21.60 \pm 12.63$ \\
\hline Working on farm & 66.8 & $38.74 \pm 11.36$ & 52.2 & $39.15 \pm 11.28$ \\
\hline Near & 64.2 & $37.84 \pm 11.36$ & 70.1 & $38.54 \pm 11.44$ \\
\hline Far & 35.8 & $40.80 \pm 9.47$ & 29.9 & $40.57 \pm 10.78$ \\
\hline Whole day & 90.0 & $40.67 \pm 9.21$ & 90.9 & $40.61 \pm 10.26$ \\
\hline Half day & 10.0 & $21.76 \pm 10.87$ & 9.1 & $24.55 \pm 10.63$ \\
\hline Working as labourer & 4.5 & $18.22 \pm 13.21$ & 4.3 & $18.04 \pm 16.07$ \\
\hline Stitching \& Others & 11.7 & $2.53 \pm 3.83$ & 14.4 & $3.77 \pm 5.80$ \\
\hline Sitting/chatting & 2.9 & $15.69 \pm 11.00$ & 3.1 & $23.23 \pm 14.85$ \\
\hline
\end{tabular}

* Of 797 pregnant women, information on activity was available for 779 and 736 at the 18th and 28th week of gestation, respectively.

† Mean value \pm standard deviation.

total daily score. About $65 \%$ of women had to collect firewood and it contributed $2.7 \%$ of the total daily activity score. Washing utensils and clothes also made a considerable contribution (about 7.9\% each).

\section{Components identified by PCA}

Initially, correlations of the activity score of each of the 14 major activities with the total daily activity score were computed (Table 2) for early (18 weeks) as well as late (28 weeks) gestation. Only eight of the 14 activities showing significant correlation with daily activity score were considered for PCA.

The factor loading matrix (results of PCA) of these eight variables is given in Table 3. In the first component, variables such as afternoon nap and watching TV/movies had high loadings along with the activities of farming and fetching firewood. Women working on farms obviously spend less time resting. Hence 'farming' activity and 'less resting' are synonymous, reflecting high activity score. Thus the first factor may be interpreted as a dimension of physical activity at 'farming'. The second component

Table 2 Correlation of 14 major activity scores with total activity score

\begin{tabular}{llcc}
\hline Activity group & Activity & 18th week & 28th week \\
\hline Resting & Sleeping (night) & 0.091 & 0.076 \\
& Afternoon nap & $0.560^{*}$ & $0.520^{*}$ \\
Womestic & Watching TV & $0.395^{*}$ & $0.379^{*}$ \\
& Cooking roties & -0.189 & -0.087 \\
& Washing clothes & $0.362^{*}$ & $0.321^{*}$ \\
& Washing utensils & $0.327^{*}$ & $0.349^{*}$ \\
& Animal care & $0.453^{*}$ & $0.431^{*}$ \\
& Fetching firewood & $0.381^{*}$ & $0.399^{*}$ \\
& Fetching water & $0.506^{*}$ & $0.543^{*}$ \\
Bther & Breast-feeding & 0.094 & 0.061 \\
& Farming & $0.832^{*}$ & $0.820^{*}$ \\
& Construction work & -0.110 & -0.052 \\
& Stitching & 0.206 & 0.091 \\
& Any other activity & -0.129 & -0.098 \\
\hline
\end{tabular}

${ }^{*} P<0.01$ 
Table 3 Factor loadings obtained by principal components analysis

\begin{tabular}{|c|c|c|c|c|c|c|}
\hline \multirow[b]{3}{*}{ Activity score for } & \multicolumn{3}{|c|}{ 18th week } & \multicolumn{3}{|c|}{ 28th week } \\
\hline & \multicolumn{3}{|c|}{ Loading for component } & \multicolumn{3}{|c|}{ Loading for component } \\
\hline & 1 & 2 & 3 & 1 & 2 & 3 \\
\hline Farming & 0.841 & & & 0.832 & & \\
\hline Resting (nap) & 0.759 & & & 0.755 & & \\
\hline Resting (TV) & 0.634 & & & 0.564 & & \\
\hline Fetching firewood & 0.578 & & & 0.505 & & \\
\hline Washing clothes & & 0.868 & & & 0.857 & \\
\hline Washing utensils & & 0.860 & & & 0.845 & \\
\hline Animal care & & & & & & \\
\hline Fetching water & & & 0.987 & & & 0.821 \\
\hline$\%$ variance & 26.6 & 21.6 & 12.6 & 25.2 & 21.7 & 14.1 \\
\hline
\end{tabular}

showed high loadings for washing clothes and utensils. Because these items are concerned with domestic activities, this factor may be interpreted as a dimension of physical activity at 'domestic' work. The third component included only the activity of fetching water. Focus group discussions held in the main study revealed that rural women perceived these activities as 'strenuous'. Therefore this component may be interpreted as a dimension of 'strenuous' physical activity. Variability in total activity explained was maximum (26.6\%) for the 'farming' dimension followed by 'domestic' (21.6\%) and then by 'strenuous' activity (12.6\%). Cumulative variability in maternal activity explained by all three factors was thus about $61 \%$. Thus, by means of PCA, three meaningful factors showing three dimensions of habitual physical activity of rural women in this community could be distinguished.

\section{$\boldsymbol{R A Q}$}

Once the components, with loading factors for various activities within them, had been identified by PCA, the activity with the highest loading from each component was considered for further analysis. Sub-questions for these three activities were thus taken into consideration while developing a new activity score (Table 4). For farming activity, sub-questions related to distance (near/far), duration (whole/half day) and frequency (daily/weekly) were considered. For the activity of washing clothes, the number for persons whose clothes were washed (less or more than five persons) and if another family member provided help (yes/no) were taken into consideration. In the case of the activity of fetching water, distance (near/midway/far), the number of containers carried at a time (less or more than three) and the number of trips per day (less or more than three) were considered. It can be seen that higher the intensity of the activity, the higher was the score allocated to it. A new activity score was defined as the sum of all scores for subquestions pertaining to these three activities. Thus a woman not doing any of these activities will have '0' score while a women doing all three activities with the highest intensity will have a maximum score of ' 17 '.

Table 4 New questionnaire and scoring system for assessing habitual physical activity of rural women in India

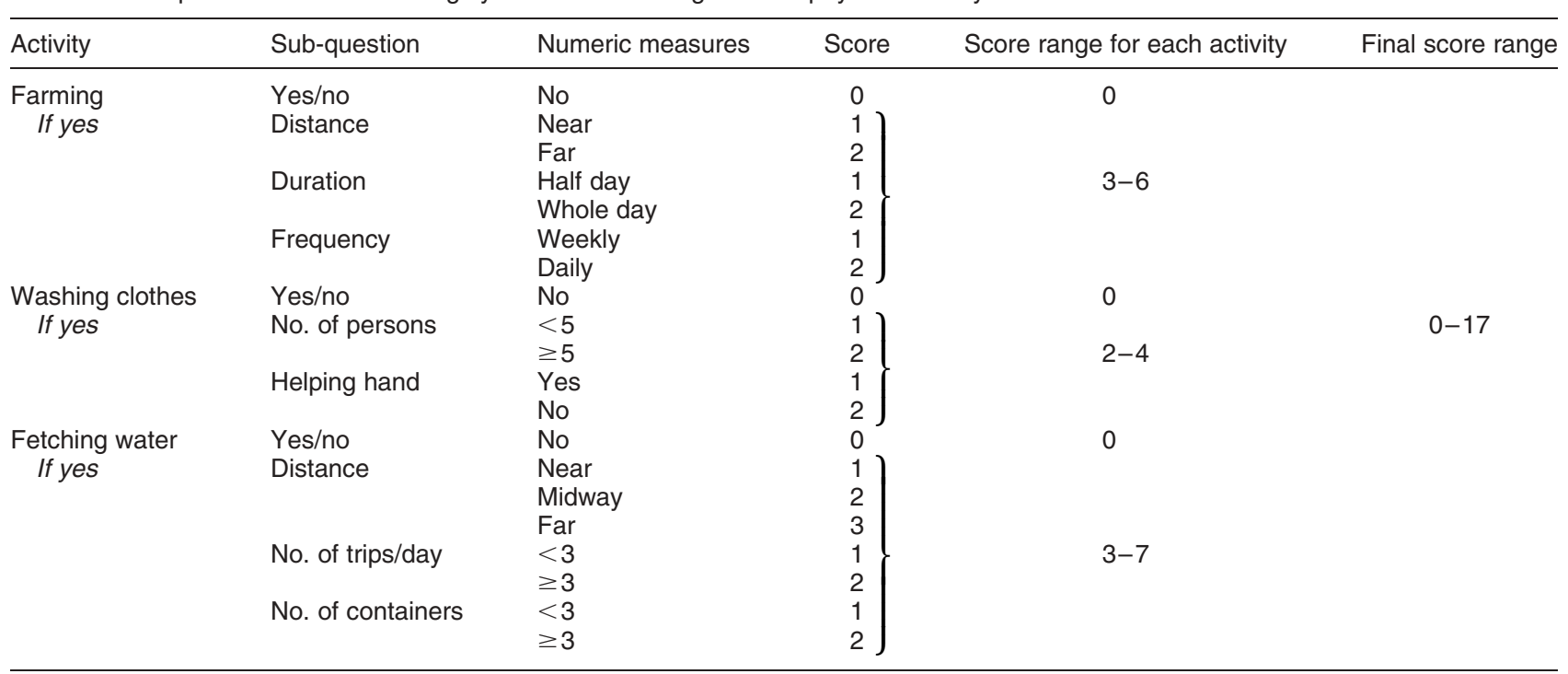


Based on tertile values of the score of this new RAQ, women were further classified into three broad categories: low, medium and high activity level.

\section{Validation of RAQ}

A valid reference method that measures physical activity independently does not exist ${ }^{17}$. Therefore, we validated the RAQ against the elaborate questionnaire as well as the observer-maintained dairy records on a sub-sample of women from the main study.

\section{With elaborate questionnaire}

Initially the questionnaire was validated with the elaborate questionnaire used in the main study as a standard. It was examined whether the women fell into similar thirds of the distribution when assessed by both questionnaires. At early gestation $68.4 \%$ while at late gestation $74.4 \%$ of the women were distributed in similar thirds by both methods, and the chi-square for cross-classification was highly significant $(P=0.000)$. In particular, comparison of the RAQ with the standard method showed that $72.2 \%$ of the women were correctly identified as being engaged in 'high' activity at early gestation, indicating the sensitivity of the RAQ. A similar comparison for correctly identifying women doing 'low' activity was $77.4 \%$, indicating the specificity of the RAQ. At late gestation, the figures for sensitivity and specificity of the RAQ were $81.2 \%$ and $79.7 \%$, respectively.

\section{With observer-maintained diary}

A more scientific validation is with data from the observermaintained diary method as a standard. In the main study, 42 women were followed by a trained nutritionist who stayed with each woman throughout the day from morning (07.00 hours) until late evening (21.00 hours) and recorded her minute-to-minute activity (including posture). New activity scores based on the RAQ were obtained for these women and compared with those obtained from the observer-maintained diary ${ }^{12}$. In this case too, when women were cross-classified by tertiles of RAQ score and activity score obtained using the observermaintained diary, $64.3 \%$ of the women were observed to be in similar thirds. The corresponding figure for sensitivity (correctly identifying women engaged in high activity) was $84.6 \%$ and for specificity (correctly identifying women engaged in low activity) was $64.3 \%$.

\section{Studying relationship of activity with birth size}

Not only is quantifying daily physical activity in field studies difficult, but also no gold standard method exists for its assessment. Therefore, one of the methods used for validation is to examine its effect on an another parameter related to it. For example, Baecke et al. ${ }^{17}$ studied the relationship of physical activity and lean body mass. Therefore, we further examined the validity of the RAQ by considering it as an independent variable for studying its relationship with birth size using multiple regression analysis. Thus MLRA was done separately for activity scores obtained by the RAQ as well as those obtained by the elaborate questionnaire, and the results were compared for indirect validation of the RAQ. This analysis was limited to the 633 women who delivered at term (Table 5).

Activity scores based on the elaborate questionnaire had shown ${ }^{12}$ that maternal activity at 18 weeks was inversely related to birth weight, head circumference, mid-arm circumference and placental weight. Similar inverse relationships with birth weight $(P=0.07)$, head circumference $(P=0.001)$, mid-arm circumference $(P=0.02)$ and placental weight $(P=0.03)$ were observed at 18 weeks' gestation using new activity scores based on the RAQ (Table 5). The magnitude of total prediction $\left(R^{2}\right)$ for various neonatal measures was also similar.

Table 5 Multiple regression analysis of the relationship* of maternal activity† with neonatal measurements among rural Indian women

\begin{tabular}{|c|c|c|c|c|c|c|c|}
\hline \multirow[b]{2}{*}{ Dependent variable } & \multirow[b]{2}{*}{ Method $†$} & \multicolumn{3}{|c|}{ Maternal activity at 18 weeks } & \multicolumn{3}{|c|}{ Maternal activity at 28 weeks } \\
\hline & & $R^{2}$ & $\beta$ & $P$ & $R^{2}$ & $\beta$ & $P$ \\
\hline \multirow[t]{2}{*}{ Birth weight } & $A$ & 24.0 & -31.4 & 0.05 & 24.7 & -38.1 & 0.02 \\
\hline & B & 24.8 & -27.9 & 0.07 & 24.3 & -23.8 & 0.14 \\
\hline \multirow[t]{2}{*}{ Length } & A & 21.6 & - & NS & 22.2 & -0.19 & 0.04 \\
\hline & $\mathrm{B}$ & 21.7 & - & NS & 21.8 & - & NS \\
\hline \multirow[t]{2}{*}{ Head circumference } & A & 25.9 & -0.16 & 0.005 & 26.2 & -0.15 & 0.009 \\
\hline & B & 26.2 & -0.18 & 0.001 & 25.8 & -0.11 & 0.055 \\
\hline \multirow[t]{2}{*}{ Triceps skinfold thickness } & $\mathrm{A}$ & 7.9 & - & NS & 7.7 & - & NS \\
\hline & $B$ & 7.6 & - & NS & 7.7 & - & NS \\
\hline \multirow[t]{2}{*}{ Mid-arm circumference } & $A$ & 11.4 & -0.10 & 0.03 & 12.1 & -0.11 & 0.01 \\
\hline & $B$ & 11.6 & -0.09 & 0.02 & 11.9 & -0.10 & 0.03 \\
\hline \multirow[t]{2}{*}{ Placental weight } & $A$ & 8.4 & -9.0 & 0.02 & 7.7 & - & NS \\
\hline & B & 8.4 & -8.3 & 0.03 & 7.6 & - & NS \\
\hline
\end{tabular}

NS - not significant.

${ }^{*}$ Adjusted for sex, parity, gestation, pre-pregnant weight, energy and protein intakes, and social status.

† Method A - total activity score based on the elaborate questionnaire is considered; method B - new activity score based on the rapid assessment questionnaire is considered. 
At 28 weeks of gestation, activity score based on the elaborate questionnaire was inversely related to birth weight, length, head circumference and mid-arm circumference. However, in the case of scores based on the RAQ, significance of the coefficient $\beta$ was seen only for head circumference $(P=0.055)$ and mid-arm circumference $(P=0.03)$. Thus, the RAQ was not able to bring out the significant effect of maternal activity on birth weight and length. Maternal activity assessed by both methods was not related to neonatal body fat, as measured by triceps skinfold thickness.

\section{Discussion}

Physical activity is an important aspect of human lifestyle. However, it is hard to quantify in epidemiological studies?. As techniques of measuring energy expenditure are not applicable to large-scale field studies, there is a growing interest in the development of techniques to investigate the health benefits of physical activity in a wide range of study designs. Physical activity questionnaires are the most popular, practical and widely used in large observational studies. Popularly, only two broad categories of physical activity - occupational and leisure-time activity - are considered. But in rural Indian communities, women perform various activities that are difficult to fit into these conventional categories. Their daily activities range from light to moderate and are important for the description of their pattern of physical activity. In the present study, we used PCA for identifying important representative activities. Based on these activities, an RAQ was developed, validated and examined for the effect of maternal activity on birth size.

PCA has been used previously to identify the meaningful underlying dimensions of physical activity ${ }^{17}$. It was also used to investigate whether various methods can measure the same facet of activity ${ }^{18}$. Our study reveals several benefits offered by this technique. First, dimensions of physical activity like 'domestic', 'farming' and 'strenuous', which were closer to the real lifestyle of Indian rural women, were identified. Second, the fact that the PCA factors remained same at 18 and 28 weeks of gestation reflects that rural mothers hardly change their activity during gestation. This confirms the observation that women from farming communities in many developing countries hardly change their activity during gestation $^{19}$, and indicates that the technique may be useful to study time-related changes in physical activity.

Often, researchers use all variables with a factor loading $>0.5$ for constructing activity indices. It is known that PCA gives clustering of variables into components such that variables within a component are logically related to one another, while those between components are independent of each other. In view of this, we selected only one activity with highest loading from each component as a representative activity for that component and developed an RAQ based on three representative activities selected in this manner. We thus highlighted a new aspect of the use of PCA in development of the rapid assessment activity questionnaire. It was observed that the RAQ developed in this way validated well with the elaborate questionnaire as well as with data from an observer-maintained diary used in the main study.

Usually the concurrent validity of activity questionnaires is examined by studying the differences in activity scores for groups with professional status 9 . In the rural Indian community, there are hardly any variations in the professional status of women. The only group that can be compared is the women who were not involved in farming. It was observed for these women that washing clothes and utensils formed the first component (explaining $28 \%$ of the variability), fetching firewood formed the second component (17\% of the variability), while fetching water formed the third component ( $14 \%$ of the variability) and afternoon rest the fourth (14\% of the variability). Thus PCA showed that, for woman not engaged in farming activity, the habitual activity pattern remains practically the same.

Activity questionnaires have been validated by showing that correlations with factors such as high-density lipoprotein cholesterol and maximum oxygen uptake were same as or better than those of the larger questionnaire $2,20,21$. In the present study, the RAQ was also validated using MLRA by examining the relationship of maternal activity with various neonatal measurements. Scores based on the RAQ that used only three main activities identified by PCA showed similar significant inverse relationships with head circumference and midarm circumference as were observed with activity assessed using an elaborate questionnaire comprising 14 major activities. At 28 weeks, although total $R^{2}$ were fairly similar, the relationship of total activity score with birth weight and length could not be seen with scores based on the RAQ. Nevertheless, it was observed that babies born to mothers who were engaged in light activity (doing only one or none of the three activities used in the RAQ) were heavier (by $100 \mathrm{~g}, P<0.05$ ), had a greater head circumference (by $0.5 \mathrm{~cm}, P<0.05$ ) and had greater mid-arm circumference (by $0.2 \mathrm{~cm}, P<0.05$ ) than babies born to mothers doing all three activities. The RAQ was thus able to discriminate between mean birth size of babies born to women engaged in light versus heavy activities, which is an additional merit for large-scale field studies. In view of this, the benefits of the RAQ based on only three leading activities identified by PCA seem to outweigh the limitation that it shows lower values and significance for birth weight and length.

The fact that the RAQ showed an inverse relationship with placental weight at the 18th week of gestation only suggests that PCA was able to identify activities having differential effects during gestation. 
In poor communities, there are some social factors that may affect the activity pattern of women. For example, since the majority of families were joint families, in this community the family size was large. Although it may increase the domestic workload of a woman, the possibility of having helping hands (motherin-law or sister-in-law) for sharing of work cannot be ruled out. When these social factors were considered in PCA, they did emerge as the second component (with a factor loading of 0.818 for family size and -0.829 for helping hand) explaining $14 \%$ of the variability at early as well as late gestation. It can be noted that while family size has a positive association with activity, helping hand shows a negative association indicating their equal importance.

In conclusion, our study reveals that very simple questionnaires based on leading factors identified by PCA can be as informative as longer and detailed questionnaires. Our findings show that the habitual physical activity of rural Indian women encompassed three distinct dimensions: farming activity, domestic activity and strenuous activity. The RAQ based on these three activities was validated in various ways and indicated the strength of PCA. Women in different communities have different activity patterns. Especially in rural communities, light to moderate activity tends to vary more but is important to the description of the pattern of habitual physical activity. If modifying maternal activity is viewed as a possible intervention for improving birth weight in rural populations, the RAQ could also be useful in evaluating the shift in the activity pattern and associated benefits of the intervention. We feel that the approach of rapid assessment of physical activity described in this study has potential for adaptation to other settings, especially rural communities in developing countries, where women have monotonous busy lives with clearly defined tasks.

\section{Acknowledgements}

The study was supported by the Welcome Trust, London, and the Medical Research Council, UK. We are grateful to Dr VS Rao, Director, Agharkar Research Institute and Dr VN Rao, Director, KEM Hospital Research Centre for providing facilities for this collaborative research.

\section{References}

1 Gopalan C. Low birth-weight: significance and implications. In: Sachdev HPS, Chaudhary P, eds. Nutrition in Children; Developing Country Concerns. New Delhi: Imprint, 1994.

2 Washburn RA, Goldfield SR, Smith KW, McKinlay JB. The validity of self-reported exercise induced sweating as a measure of physical activity. American Journal of Epidemiology 1990; 132: 107-13.

3 Warwick PM, Macqueen SE. Retrospective assessment of level of activity and energy expenditure - a pilot study. Proceedings of the Nutrition Society of Australia 1988; 13: 149 .
4 Schoeller DA, Racette SB. A review of field techniques for the assessment of energy expenditure. Journal of Nutrition 1990; 120(Suppl.): 1492-5.

5 Bernstein M, Sloutskis D, Kumanyika S, Sparti A, Schutz Y, Morabia A. A data-based approach for developing a physical activity frequency questionnaire. American Journal of Epidemiology 1998; 147: 147-54.

6 Kannel WB, Sorlie P. Some health benefits of physical activity. The Framingham study. Archives of Internal Medicine 1979; 139: 857-61.

7 Reiff GG, Montoye HJ, Remington RD, Napier JA, Metzner HL, Epstein FH. Assessment of physical activity by questionnaire and interview. In: Karvonan MJ, Barry AJ, eds. Physical Activity and The Heart. . Springfield, IL: Charles C Thomas, 1967; 336-72.

8 Taylor HL, Jacobs DR Jr, Schucker B, Knudsen J, Leon AS, Debacker G. Assessment of leisure time physical activities. Journal of Chronic Diseases 1978; 31: 744-55.

9 Phillippaerts RM, Lefevre J. Reliability and validity of three physical activity questionnaires in Flemish males. American Journal of Epidemiology 1998; 147: 980-90.

10 Paffenbarger RS Jr, Blair SN, Lee IM, Hyde RT. Measurement of physical activity to assess health effects in free living populations. Medicine and Science in Sports and Exercise 1993; 25: 50-70.

11 Aaron DJ, Kriska AM, Dearwater SR, Cauley JA, Metz KF, LaPorte RE. Reproducibility and validity of an epidemiologic questionnaire to assess past year physical activity in adolescents. American Journal of Epidemiology 1995; 142 191-201.

12 Rao S, Kanade A, Margetts BM, Yajnik CS, Lubree H, Rege S, et al. Maternal activity in relation to birth size in rural India: the Pune Maternal Nutrition Study. European Journal of Clinical Nutrition 2003; 57: 531-42.

13 Gopalan C. Growth of Affluent Indian Girls during Adolescence. Scientific Report No. 10. New Delhi: Nutrition Foundation of India, 1989.

14 World Health Organization (WHO). Physical Status: The Use and Interpretation of Anthropometry. Report of a WHO Expert Committee. Geneva: WHO, 1985.

15 Rao S, Yajnik CS, Kanade AN, Fall CH, Margetts BM, Jackson $\mathrm{AA}$, et al. Intake of micronutrient-rich foods in rural Indian mothers is associated with the size of their babies at birth: Pune Maternal Nutrition Study. Journal of Nutrition 2001; 131: $1217-24$.

16 Lawrence M, Singh J, Lawrence F, Whitehead RG. The energy cost of common daily activities in African women: increased expenditure in pregnancy? American Journal of Clinical Nutrition 1985; 42: 753-63.

17 Baecke JAH, Burema J, Frijters JER. A short questionnaire for the measurement of habitual physical activity in epidemiological studies. American Journal of Clinical Nutrition 1982; 36: $936-41$.

18 Pols MA, Peeters PH, Kemper HC, Collette HJ. Repeatability and relative validity of two physical activity questionnaires in elderly women. Medicine and Science in Sports and Exercise 1996; 28: 1020-5.

19 Heini A, Schutz Y, Diaz E, Prentice AM, Whitehead RG, Jequier E. Free-living energy expenditure measured by two independent techniques in pregnant and nonpregnant Gambian women. American Journal of Physiology 1991; 261: E9-17.

20 Siconolfi SF, Lasater TM, Snow RC, Carleton RA. Selfreported physical activity compared with maximal oxygen uptake. American Journal of Epidemiology 1985; 122: $101-5$.

21 Kohl HW, Blair SN, Paffenbarger RS Jr, Macera CA, Kronenfeld JJ. A mail survey of physical activity habits as related to measured physical fitness. American Journal of Epidemiology 1988; 127: 1228-39. 


\section{Appendix}

Date: / /

Total no. of persons in house:

No. of helping hands:

Woman works on farm:

Name of CWW:
Maternal Activity Questionnaire (Visit no.)

$\begin{array}{ll} & \text { Name of subject: } \\ \text { Couple number: } & \text { Coume of village: }\end{array}$

\begin{tabular}{|c|c|c|c|c|}
\hline Category & Activity & Description & Numeric measures & Score \\
\hline \multirow[t]{11}{*}{ Resting } & \multirow[t]{3}{*}{ Night sleep } & \multirow[t]{3}{*}{ No. of hours } & $<6$ & 12 \\
\hline & & & $6-8$ & 9 \\
\hline & & & $\geq 8$ & 6 \\
\hline & \multirow[t]{3}{*}{ Afternoon nap } & \multirow[t]{3}{*}{ No. of hours } & 0 & 7 \\
\hline & & & $0-1$ & 6 \\
\hline & & & $1-2$ & 5 \\
\hline & \multirow[t]{5}{*}{ Watching TV } & No. of programmes & 0 & 7 \\
\hline & & \multirow[t]{4}{*}{ No. of movies in a week } & 1 & 5.5 \\
\hline & & & 2 & 5.0 \\
\hline & & & 3 & 4.5 \\
\hline & & & $\geq 3$ & 4.0 \\
\hline \multirow[t]{17}{*}{ Domestic } & \multirow[t]{3}{*}{ Cooking } & No. of roties & $<10$ & 2.3 \\
\hline & & Morning & $10-20$ & 3.0 \\
\hline & & Evening & $\geq 20$ & 5.5 \\
\hline & \multirow[t]{3}{*}{ Washing clothes } & No. of persons & $<5$ & 3.5 \\
\hline & & \multirow[t]{2}{*}{ Helping hand* (yes/no) } & $5-10$ & 7.0 \\
\hline & & & $\geq 10$ & 8.0 \\
\hline & \multirow[t]{3}{*}{ Washing utensils } & No. of persons & $<5$ & 3.5 \\
\hline & & \multirow[t]{2}{*}{ Helping hand* (yes/no) } & $5-10$ & 7.0 \\
\hline & & & $\geq 10$ & 8.0 \\
\hline & Care of animals & No. of animals & Number & Number $\times 1$ \\
\hline & & No. of milking animals & & \\
\hline & \multirow[t]{2}{*}{ Fetching firewood } & Distance: near/far & Near & 3 \\
\hline & & Daily/weekly frequency† & Far & 6 \\
\hline & \multirow[t]{3}{*}{ Fetching water } & Distance: near/midway/far & Near & $2 \times$ no. of trips \\
\hline & & No. of trips/day & Midway & $4 \times$ no. of trips \\
\hline & & No. of containers $\ddagger$ & Far & $6 \times$ no. of trips \\
\hline & Breast-feeding & Frequency & Frequency & Frequency $\times 0.5$ \\
\hline \multirow[t]{11}{*}{ Other } & \multirow[t]{6}{*}{ Farming } & Distance: near/far & Near & \\
\hline & & Whole/half day & Whole day & 38.5 \\
\hline & & Daily/weekly frequency $†$ & Half day & 20.5 \\
\hline & & & Far & \\
\hline & & & Whole day & 41.0 \\
\hline & & & Half day & 23.0 \\
\hline & \multirow[t]{2}{*}{ Labourer/construction/sand worker } & Whole/half day & Whole day & 42 \\
\hline & & Daily/weekly frequency† & Half day & 24 \\
\hline & Stitching: machine/manually & $\begin{array}{l}\text { Daily/weekly frequency } † \\
\text { (no. of hours) }\end{array}$ & Hours & Hours $\times 18$ \\
\hline & Activities other than farming & Making pappadam/vermicelli & Hours & Hours $\times 18$ \\
\hline & & $\begin{array}{l}\text { Daily/weekly frequency } † \\
\text { (no. of hours) }\end{array}$ & & \\
\hline
\end{tabular}

* In the case of a helping hand being available, the activity score is reduced by half.

† For activities performed weekly, the activity score is multiplied by (respective frequency/7)

$\ddagger$ In the case of more than one container carried at a time, the activity score is multiplied by the number of containers. 